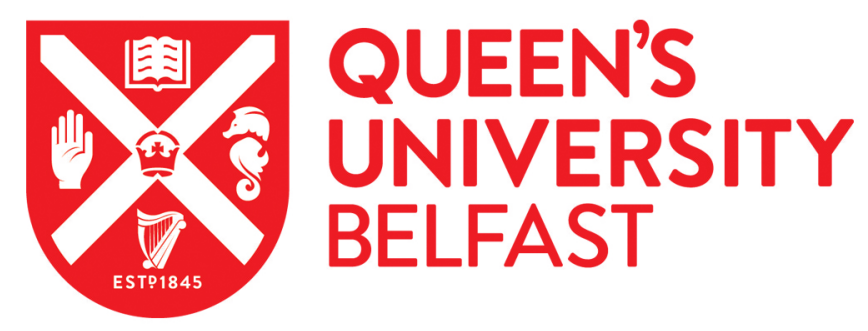

\title{
Specific Monoclonal Antibody-Based Enzyme Immunoassay for Sensitive and Reliable Detection of Alternaria Mycotoxin Iso- Tenuazonic Acid in Food Products
}

Xiao, Z-L., Wang, Y-L., Shen, Y-D., Xu, Z-L., Dong, J-X., Wang, H., Situ, C., Wang, F., Yang, J-Y., Lei, H-T., \& Sun, Y-M. (2017). Specific Monoclonal Antibody-Based Enzyme Immunoassay for Sensitive and Reliable Detection of Alternaria Mycotoxin Iso-Tenuazonic Acid in Food Products. Food Analytical Methods, 11(3), 635645. https://doi.org/10.1007/s12161-017-1033-9

\section{Published in:}

Food Analytical Methods

\section{Document Version:}

Peer reviewed version

Queen's University Belfast - Research Portal:

Link to publication record in Queen's University Belfast Research Portal

\section{Publisher rights}

(C) 2017 Springer Science+Business Media, LLC.

This work is made available online in accordance with the publisher's policies. Please refer to any applicable terms of use of the publisher.

\section{General rights}

Copyright for the publications made accessible via the Queen's University Belfast Research Portal is retained by the author(s) and / or other copyright owners and it is a condition of accessing these publications that users recognise and abide by the legal requirements associated with these rights.

Take down policy

The Research Portal is Queen's institutional repository that provides access to Queen's research output. Every effort has been made to ensure that content in the Research Portal does not infringe any person's rights, or applicable UK laws. If you discover content in the

Research Portal that you believe breaches copyright or violates any law, please contact openaccess@qub.ac.uk. 
1 Specific monoclonal antibody based enzyme immunoassay for

2 sensitive and reliable detection of Alternaria Mycotoxin

3 Iso-Tenuazonic Acid in food products

4 Zhi-Li Xiao ${ }^{a, \dagger}$, Ya-Li Wang a, ${ }^{\text {, }}$, Yu-Dong Shen ${ }^{a}$, Zhen-Lin Xu ${ }^{\text {a }}$, Jie-Xian Dong a,b,

5 Hong Wang ${ }^{\text {a,*}, \text { Chen Situ }}{ }^{\mathrm{c},}$, Feng Wang ${ }^{\text {a, }}$, Jin-Yi Yang ${ }^{\text {a }}$, Hong-Tao Lei a , and

6 Yuan-Ming Sun ${ }^{\mathrm{a}}$

$7 \quad{ }^{a}$ Guangdong Provincial Key Laboratory of Food Quality and Safety, South China

8 Agricultural University, Guangzhou 510642, China

9 b Department of Entomology and Nematology and UCD Comprehensive Cancer

10 Center, University of California, Davis, California 95616, United States

11 c Institute for Global Food Security, School of Biological Sciences, Queen's

12 University Belfast, Belfast, BT7 1NN, Northern Ireland, UK

13 †Equal contributors.

14 *Corresponding Author

15 Tel: +86208528 3448. Fax: +862085280270.

16 E-mail address: gzwhongd@163.com (H. W.)

$17 \quad \ddagger$ Second Corresponding Author

18 E-mail: c.situ@qub.ac.uk 
21 ABSTRACT: In this paper, we report the development of a sensitive and specific monoclonal antibody based immunodiagnostic method for the detection of iso-tenuazonic acid (ITeA), an Alternaria mycotoxin, in food samples. The ITeA was derivatized with hydrazine hydrate to produce the antigen (E)-3-(1-hydrazonoethyl)-4-hydroxy-5-isobutyl-1H-pyrrol-2(5H)-one (ITeAH) which was further reacted with glyoxalic acid to generate the hapten (E)-2-((Z)-(1-(4-hydroxy-5-isobutyl-2-oxo-2,5-dihydro-1H-pyrrol-3-yl)ethylidene) (ITeAHGA) which was used as an immunogen after conjugation to bovine serum albumin (BSA). A highly specific monoclonal antibody selectively binding to ITeAH was generated via the hybridoma technique and subsequently used to construct a heterologous indirect competitive enzyme-linked immunosorbent assay (icELISA) using ITeAH as the competitive antigen for the detection of ITeA with a limit of detection (LOD) of $0.5 \mathrm{ng} / \mathrm{mL}$. Under the optimum conditions, the developed icELISA is highly sensitive $\left(\mathrm{IC}_{50}=7.8 \mathrm{ng} / \mathrm{ml}\right)$ with recovery rates ranged from 82.3 to $109.8 \%$ for spiked food samples. The comparative analysis of results revealed a good correlation between the icELISA and the standard HPLC-MS/MS method, confirming the suitability of the developed icELISA for screening and detection of mycotoxin ITeA in food samples.

KEYWORDS: iso-tenuazonic acid; monoclonal antibody; enzyme-linked immunosorbent assay; mycotoxin 


\section{Introduction}

Tenuazonic acid (TeA) and its isomer, iso-tenuazonic acid (ITeA), are major metabolic toxic products of Alternaria and other fungal species such as Aspergillus flavus, Pyricularia oryzae, and Phoma sorghina (Qiang et al. 2008; Marin et al. 2013). Owing to their ability of growth at low temperature, Alternaria species are responsible for spoilage of food plants during refrigerated transport and storage, whilst some Alternaria mycotoxins are heat-resistant even at relatively high temperature of $230^{\circ} \mathrm{C}$ and thus can not be detoxicated by cooking (Siegel et al. 2010). TeA-producing fungi are ubiquitous in many biological environments and capable of infecting most plant species including food crops. In fruits and vegetables, TeA has the highest contamination frequency and is present in higher concentrations compared to other Alternaria toxins (EFSA 2011). In spite of being cautious pathogens of many plant diseases, genotoxic and fetotoxic in rats, as well as being linked to the development of oesophageal cancer, currently there are no regulations on Alternaria toxins in food and feed in Europe or in other regions of the world. Furthermore, TeA is considered the most acutely toxic Alternaria mycotoxins (Shephard et al. 2012). Because of the similarities in chemical structure, it is speculated that ITeA and TeA are of similar toxicological relevance. For instance, they both exhibit remarkable toxic effects on Artemia salina with mortality rates of $68.9 \%$ and $73.6 \%$, respectively (Qin et al. 2009). Not only the antibacterial activity of ITeA is identical to TeA (Gitterman 1965), ITeA also exhibits significant phytotoxicity inhibiting plant growth and promoting leaf browning (Lebrun et al. 1988).

It was reported that some naturally contaminated food commodities contained only 4\% ITeA in their total TeA content (Asam et al. 2013), but the high level of ITeA in 
sorghum based infant food has raised increasing concerns and more samples should be analyzed to elucidate if there is a general tendency related to sorghum (Qiang et al. 2008). Nevertheless, TeA has been found to be the predominant Alternaria mycotoxin detected in China in all tomato ketchup $(10.2-1781 \mu \mathrm{g} / \mathrm{kg})$ and tomato juice samples (7.4-278 $\mu \mathrm{g} / \mathrm{kg}$ ) and in $99.4 \%$ of wheat flour (1.76-520 $\mu \mathrm{g} / \mathrm{kg})$ (Zhao et al. 2015a,b). Therefore, the total exposure of ITeA can not be neglected due to its acute toxicity and potential harmful effects on human and animal health.

Subsequently, it is necessary to continually monitor ITeA and TeA in fruits, vegetables, cereals and oleaginous plants intended for human consumption and feed production (Qiang et al. 2008). Although several instrumental methods exist for measuring of TeA and its analouges (Noser et al. 2011; Siegel et al. 2009; Asam et al. 2011; Prelle et al. 2013), LC-MS is the only instrumental technique available for ITeA (Asam et al. 2013). The method simultaneously detects both TeA and ITeA after their derivatization with 2,4-dinitrophenylhydrazine. While instrumental methods can offer a high level of precision and accuracy, the sophistication aspect of such analytical tools rendering their limited applications in routine and high throughput analysis. Immunochemical methods, on the other hand, are simple and cost effective, yet sensitive and rapid, enabling for a large array of sample screening. Immunoassay for TeA has recently been described in a couple of studies (Gross et al. 2011; Yang et al. 2012). Production of an antibody to the analyte is essential to an immunoassay. Compared with polyclonal antibody which is widely used in immunoassay, monoclonal antibody is more specific and homogenous, also more difficult to produce. There is no report on ITeA immunoassay based on monoclonal antibody available to date to the best of our knowledge. The present study therefore aimed to develop a sensitive and specific immunochemical screening method and monitor ITeA in food 
products.

In the present study, two novel ITeA haptens, ITeAH and ITeAHGA (Fig.1), were adopted to develop a specific anti-ITeAH antibody, using ITeAHGA as a hapten to prepare the immunogen by coupling to a carrier protein (BSA). A highly specific monoclonal antibody (mAb) selectively binding to ITeAH, was generated via the hybridoma technique and was subsequently used to develop an icELISA for the detection of ITeA. Various ELISA conditions were optimized and performance of the assay was evaluated by measuring ITeA in real food samples.

\section{Materials and methods}

\subsection{Reagents and Chemicals}

Leucine, bovine serum albumin (BSA), dicyclohexylcarbodiimide(DCC), N-hydroxysuccinimide(NHS), polyethylene glycol (PEG) 2000, ovalbumin (OVA), 3,3',5,5'-tetramethylbenzidine(TMB), complete and incomplete Freund's adjuvants, hypoxanthine-aminopterin-thymidine (HAT), hypoxanthine-thymidine (HT), culture media RPMI-1640, and pristane were obtained from Sigma (St. Louis, MO, USA). The mouse SP2/0 myeloma cell line was sourced from the Sun Yat-sen University (Guangzhou, China). Tween-20, N,N-Dimethylformamide (DMF), sodium ethylate, diketene, benzene, ethyl acetate, chloroform, hydrazine hydrate, methanol, glutaric dialdehyde, and 4-hydroxybenzaldehyde were purchased from Guangzhou Chemical Reagent Factory (Guangzhou, China). Horseradish peroxidase-labeled goat anti-mouse IgG (IgG-HRP) was obtained from Boster Biotech Co., Ltd. (Wuhan, China). Polystyrene microtiter plates were sourced from Jiete Biotech Co., Ltd. (Guangzhou, China). Microwell plates for cell culture were obtained from Corning Incorporated (New York, USA). All organic solvents and chemicals used were of analytical grade. Female Balb/c mice were purchased from Guangdong Medical 
Laboratory Animal Center. The mycotoxin standards of AOH, AME were purchased from Taileqi Technology Co., Ltd. (Beijing, China) and TeA, ITeA, ITeAH were synthesized in Guangdong Provincial Key Laboratory of Food Quality and Safety (Guangzhou, China).

\subsection{Buffers and Solutions}

Buffers were prepared and used as follows: $10 \mathrm{mmol} / \mathrm{L}$ PBST (PBS buffer containing $0.1 \%$ Tween-20) for washing; $50 \mathrm{mmol} / \mathrm{L}$ carbonate buffer $(\mathrm{pH} \mathrm{9.6)} \mathrm{for}$ coating, 5\% of skimmed milk powder in PBS buffer for blocking, sodium phosphate buffers ( $\mathrm{pH}$ 5.4) as general diluent, and $2 \mathrm{~mol} / \mathrm{L} \mathrm{H}_{2} \mathrm{SO}_{4}$ was used as the stop solution. Chromogenic reagent was prepared using $150 \mu \mathrm{L}$ of the TMB solution $(15 \mathrm{mg} / \mathrm{mL}$ in DMF) and $2.5 \mu \mathrm{L}$ of $6 \%(\mathrm{w} / \mathrm{v}) \mathrm{H}_{2} \mathrm{O}_{2}$ in $10 \mathrm{~mL}$ of $0.1 \mathrm{~mol} / \mathrm{L}$ citrate.

\subsection{Instruments}

Centrifuge (5810R) was purchased from Eppendorf Company, USA. The LC-MS/MS analysis was carried out using a 1,200 series LC system (Agilent, USA) equipped with the Agilent 6410 Triple Quad LC-MS System. The analytical column was $2.1 \mathrm{~mm} \times 150 \mathrm{~mm}, 3.5 \mu \mathrm{m}$ Zorbax SB-C18. Nuclear magnetic resonance (NMR) spectra were obtained with DRX-600 NMR spectrometers (Bruker, Germany-Switzerland). Ultraviolet-visible (UV-vis) spectra were recorded on a UV-160A Shimadzu spectrophotometer (Kyoto, Japan). Microtiter plates were washed using a Multiskan MK2 microplate washer (Thermo Labsystems, USA). The Optical Density (OD) of ELISA signals were measured using a Perkin Elmer 1420 Multi-label Analyzer (USA). Wrist-action shaker (Vortex Genius3) was a product of IKA Company, Germany.

\subsection{Synthesis and Characterization of Haptens}

\subsubsection{ITeA synthesis}


ITeA was synthesized according to the method previously described (Yang et al. 2012) (Fig. 2). After recrystallization in chloroform, a white needle solid was obtained with a $38.6 \%$ yield. The ITeA structure was confirmed by APCI-MS and NMR analysis. Two haptens namely, $\mathrm{ITeAH}$ ((E)-3-(1-hydrazonoethyl)-4-hydroxy-5-isobutyl-1H-pyrrol-2(5H)-one) and ITeAHGA ((E)-2-((Z)-(1-(4-hydroxy-5-isobutyl-2-oxo-2,5-dihydro-1H-pyrrol-3-yl)ethylidene)hyd razono)acetic acid) were subsequently synthesized following the procedures shown in Fig. 2.

\subsubsection{ITeAH synthesis}

The synthesis was carried out by the Wolff-Kishner reaction. Briefly, ITeA (1.85 g, $10 \mathrm{mmol}$ ) was dissolved in $20 \mathrm{~mL}$ chloroform and added dropwise into the flask containing $20 \mathrm{~mL}$ of hydrous hydrazine hydrate. After mixing for $1 \mathrm{~h}, 20 \mathrm{~mL}$ distilled water was added, and the mixture was then extracted twice with chloroform. The organic phase was then washed with water and dried over anhydrous magnesium sulfate. The solvent was removed to obtain a gray solid of ITeAH with a $65 \%$ yield.

\subsubsection{ITeAHGA synthesis}

The mixture of ITeAH (1.99 g, $10 \mathrm{mmol})$ and 2-oxoacetic acid (0.89 g, $12 \mathrm{mmol})$ was dissolved in $20 \mathrm{~mL}$ chloroform and agitating for $2 \mathrm{~h}$ to produce a white solid of ITeAHGA, with a 48\% yield.

\subsection{Preparation and characterization of hapten-protein conjugates}

The ITeAH hapten was conjugated to OVA via the glutaraldehyde method (Hamajima et al. 1995) in the following procedures and used as a coating antigen: OVA $(1.66 \mu \mathrm{mol} / \mathrm{L})$ and ITeAH $(166 \mu \mathrm{mol} / \mathrm{L})$ were first prepared in PBS (pH7.4), and $60 \mu \mathrm{L}$ of glutaric dialdehyde was then added dropwise. The mixture was gently stirred for $12 \mathrm{~h}$ at $4^{\circ} \mathrm{C}$ and purified by dialyzes against PBS (10 mmol/L, $\left.\mathrm{pH} 8.0\right)$ for two days. 
The dialyzed product was centrifuged for $10 \mathrm{~min}$ and the supernatant was collected and stored at $4{ }^{\circ} \mathrm{C}$. The structures of the final conjugates were confirmed by a UV-vis (200-500 nm) spectroscopy.

The ITeAHGA hapten was conjugated to BSA and OVA via the active ester method (McAdam et al. 1992) to prepare the immunogen and coating antigen, respectively. Briefly, ITeAHGA $(0.166 \mu \mathrm{mol})$, DCC $(0.122 \mu \mathrm{mol})$, and NHS $(0.122 \mu \mathrm{mol})$ were dissolved in $1.0 \mathrm{~mL}$ of $\mathrm{DMF}$ and the mixture was gently stirred at $4^{\circ} \mathrm{C}$ overnight. After centrifugation for $10 \mathrm{~min}, 500 \mu \mathrm{L}$ of the supernatant was collected and added dropwise to $10 \mathrm{~mL}$ of PBS (10 mmol/L, $\mathrm{pH}$ 8.0) containing BSA or OVA ( with mole ration of carrier protein to antigen at $1: 60$ ). The mixture was agitated at $4{ }^{\circ} \mathrm{C}$ for $12 \mathrm{~h}$ and purified by dialyzes against PBS (10 mmol/L, $\mathrm{pH} 8.0)$ for two days. After centrifugation for $10 \mathrm{~min}$, the supernatant was collected and stored at $4^{\circ} \mathrm{C}$. Formation of the conjugate was confirmed with a UV-vis spectroscopy.

\subsection{Production of $m A b$}

Six-week-old female Balb/c mice were immunized at multiple sites with $50 \mu \mathrm{g}$ of ITeAHGA-BSA conjugate emulsified in complete Freund's adjuvant. Booster injections were given at 2-week intervals with the same amount of conjugate emulsified in incomplete Freund's adjuvant. Mice were tail bled, and the quality of the antiserum was assessed using an indirect ELISA. The mouse with the highest titer received a final intraperitoneal injection of $100 \mu \mathrm{g}$ of immunogen conjugate (without adjuvant) three days prior to cell fusion.

Cell fusion procedures were performed as described by Moreno et al. (2001). The spleen cells $\left(10^{8}\right.$ cells $)$ from the selected mouse were mixed with SP2/0 myeloma cells $\left(10^{7}\right.$ cells) at a 10:1 ratio in 50\% (w/v) PEG 2000. The fused cells were distributed in 96-well plates and cultured in HAT selection medium at $37^{\circ} \mathrm{C}$ in a humidified $5 \% \mathrm{CO}_{2}$ 
incubator.

When the hybridoma cells reached around $30-40 \%$ confluence, culture supernatants were screened for their binding activities to ITeAHGA-OVA with an indirect ELISA. The hybridomas showing the desired specificity were sub-cloned for multiple rounds by the limiting dilution method until a pure and stable antibody-producing clone was obtained. The positive clones were injected into female Balb/c mice to obtain ascitic fluid for antibody production. Antibodies in the fluid were purified by the caprylic acid-ammonium sulfate precipitation method (Zhao et al. 2002) and stored at $-20^{\circ} \mathrm{C}$.

\subsection{Indirect Competitive ELISA (icELISA)}

\subsection{1 icELISA Protocol}

Ninety-six well microtiter plates were coated with $100 \mu \mathrm{L} /$ well of ITeAH-OVA overnight at room temperature. The plates were washed and incubated with 120 $\mu \mathrm{L} /$ well of blocking solution for $3 \mathrm{~h}$ at $37^{\circ} \mathrm{C}$. After washing, $50 \mu \mathrm{L}$ of the standard solution or sample extracts along with $50 \mu \mathrm{L}$ of antibodies were added. Plates were incubated for 40 min and washed. Goat anti-mouse IgG-HRP was added (100 $\mu \mathrm{L} /$ well) and incubated for $30 \mathrm{~min}$ at $37^{\circ} \mathrm{C}$. After washing, $100 \mu \mathrm{L}$ of the chromogenic reagent was added and incubated for $10 \mathrm{~min}$. The reaction was stopped by adding $50 \mu \mathrm{L}$ of stop solution, and the absorbance was measured at $450 \mathrm{~nm}$ using a Plate Reader.

The results were expressed as the percentage of inhibition $\left(\mathrm{B} / \mathrm{B}_{0}\right)$, where $\mathrm{B}$ and $\mathrm{B}_{0}$ are the absorbance values of the wells with and without standard solution, respectively. The competitive standard curve was constructed by plotting the $\mathrm{B} / \mathrm{B}_{0}$ values against the logarithm of analyte concentration. Sigmoid curve was obtained using OriginPro 8.5 software (OriginLab Corp., Northampton, USA). The limit of detection (LOD) was determined as the $10 \%$ inhibiting concentration $\left(\mathrm{IC}_{10}\right)$ (Henniona and Barcelob 1998). The linear range was defined as the detection regime between the lower and 
upper limits of quantification, i.e., the $\mathrm{IC}_{20}-\mathrm{IC}_{80}$ working range.

\subsubsection{Optimization of Assay Conditions}

The most sensitive reaction condition of the icELISA assay was achieved when using ITeAHGA-BSA, ITeAH-OVA, and ITeAH as the immunogen, coating antigen, and competition analyte, respectively. Other experimental parameters were also optimized to further improve the assay sensitivity including checkerboard titrations of coating antigens and antibody dilutions, different incubation time of antigen-antibody and secondary antibodies, as well as various buffer systems.

\subsection{Cross reactivity}

The specificity of the generated monoclonal antibody was assessed for its cross-reaction rate $(\mathrm{CR})$ with a group of structurally similar analogues based on the IC50 data calculated according to the following equation (Cui et al. 2011):

$$
C R(\%)=\frac{I C_{50 I T e A H}}{I C_{50 \text { structural analogue }}} \times 100 .
$$

\subsection{Sample Collection and Preparation}

Twenty samples were obtained from the local supermarket, apple juice $(n=5)$, beer $(n=5)$, tomato ketchup $(n=4)$, and dried fruit $(n=6)$. The liquid samples $(1 \mathrm{~mL})$ were extracted with $2 \mathrm{~mL}$ of chloroform on a wrist-action shaker for $1 \mathrm{~min}$. This was repeated two times followed by centrifugation $(1,000 \times \mathrm{g}, 10 \mathrm{~min})$. The dried fruit samples were extracted with 2:3:3 methanol-acetonitrile-water $(\mathrm{v} / \mathrm{v} / \mathrm{v})$ for $25 \mathrm{~min}$ and 4:1 chloroform-ethanol (v/v) for 1 min successively at room temperature (Stinson et al. 1981). ITeA in the samples was first reduced to ITeAH using hydrazine hydrate prior to detection using the following procedures. The organic phase containing the ITeA was mixed with $100 \mu \mathrm{L}$ hydrazine hydrate and vigorously agitated for $30 \mathrm{~min}$ at room temperature. The reaction was stopped by addition of $500 \mu \mathrm{L}$ of $\mathrm{H}_{2} \mathrm{O}$ and the mixture was transferred into a $25 \mathrm{~mL}$ round-bottom flask where the solvent was 
evaporated to dryness in a rotary evaporator at $60^{\circ} \mathrm{C}$ under reduced pressure. The residue was then resuspended in $1 \mathrm{~mL} \mathrm{H}_{2} \mathrm{O}$. To eliminate sample matrix effects, the apple juice, beer solution and the tomato ketchup was further diluted 35-45 times with the assay buffer prior to icELISA analysis. All samples were subject to analysis by both icELISA and HPLC-MS/MS.

\subsection{Recovery tests}

ITeA was added to apple juice $(1 \mathrm{~mL})$ to give the final concentrations at 30,150 , $300 \mathrm{ng} / \mathrm{mL}$, respectively. For the beer sample $(1 \mathrm{~mL})$ and tomato ketchup $(1 \mathrm{~g})$, the final concentrations were $150,300,720 \mathrm{ng} / \mathrm{mL}$ or $\mathrm{ng} / \mathrm{g}$, respectively. All of the spiked samples were prepared as described in 2.9 and measured with the developed icELISA.

Calibration curve was constructed with a serial dilutions of ITeAH $(0,0.064,0.32,1.6$, 8, 40, 200, and 1,000 $\mathrm{ng} / \mathrm{mL}$ ) and used to measure the concentration of ITeA from different extracted samples based on the reduction rate of $65 \%$ (ITeA to ITeAH).

\subsection{HPLC-MS/MS analysis}

The mobile phase was a mixture of the ammonium formate solution $(5 \mathrm{mmol} / \mathrm{L}$ in water, adjusted to $\mathrm{pH} 7.8$ with ammonia) (A) and acetonitrile (B), which was used in the following linear binary gradient: $0-3 \mathrm{~min}, 5 \% \mathrm{~B} ; 3-5 \mathrm{~min}, 5-15 \% \mathrm{~B} ; 5-8 \mathrm{~min}$, $15 \%-100 \% \mathrm{~B}$; and $8-11 \mathrm{~min}, 100 \% \mathrm{~B}$. The injection volume and flow rate were $50 \mu \mathrm{L}$ and $0.4 \mathrm{~mL} / \mathrm{min}$, respectively. Analytes were determined by ESI-MS/MS in the positive mode. Other parameters were as follows: gas temperature, $350^{\circ} \mathrm{C}$; gas flow, $10 \mathrm{~L} / \mathrm{min}$; nebulizer gas, $50 \mathrm{psi}$; and capillary voltage, $3.5 \mathrm{kV}$.

\section{Results and discussion}

\subsection{Hapten Synthesis and Conjugate Preparation}

The design and production of functional haptens is the first and a critical step in any immunoassay development. Similar to many other small molecules, ITeA (197 Da) is 
not immunogenic itself and lacks an available chemical group for protein conjugation. In this work, two novel ITeA haptens is illustrated (Fig.2). An intermediate hapten ITeAH was first prepared by condensation of hydrazine hydrate to the ketone group of ITeA. It was then reacted with glyoxalic acid to introduce the carboxyl group to obtain the tentative hapten ITeAHGA with a short aliphatic spacer arm. It has been suggested that a linear interval arm with aliphatic linkers comprised of a semi-rigid unsaturated double bond structure with three to six carbon atoms is generally good for producing the desired antibodies (Shen et al. 2007; Mercader et al. 2008). Using the same strategy, we previously reported the successful production of anti-TeA antibody and subsequently development of an ELISA for TeA (Yang et al. 2012). The successful syntheses of ITeA, ITeAH, and ITeAHGA were confirmed by MS and NMR data.

ITeA: APCI-MS, m/z 196.4 ([M-H] $\left.]^{-}\right) .{ }^{1} \mathrm{H}$ NMR (600 MHz, $\left.\mathrm{CDCl}_{3}, \mathrm{TMS}\right): \delta 0.96(\mathrm{~d}$, $\left.J=6.37 \mathrm{~Hz}, 3 \mathrm{H}, \mathrm{CH}_{3}\right), 0.98\left(\mathrm{~d}, J=6.46 \mathrm{~Hz}, 3 \mathrm{H}, \mathrm{CH}_{3}\right), 1.45(\mathrm{~m}, 1 \mathrm{H}, \mathrm{CH}), 1.84-1.67$ (m, 2H, $\left.\mathrm{CH}_{2}\right), 2.46\left(\mathrm{~s}, 3 \mathrm{H}, \mathrm{CH}_{3}\right), 3.85(\mathrm{ddd}, J=9.80,3.59,0.88 \mathrm{~Hz}, 1 \mathrm{H}, \mathrm{CH})$, and $6.03(\mathrm{~s}$, br, $1 \mathrm{H}, \mathrm{NH})$.

ITeAH: The APCI-MS was m/z 212.1 $\left([\mathrm{M}+\mathrm{H}]^{+}\right)$. The ${ }^{1} \mathrm{H}$ NMR $\left(600 \mathrm{MHz}, \mathrm{CDCl}_{3}\right.$, TMS): $\delta 0.96\left(\mathrm{~d}, J=6.43 \mathrm{~Hz}, 3 \mathrm{H}, \mathrm{CH}_{3}\right), 0.95\left(\mathrm{~d}, J=6.34 \mathrm{~Hz}, 3 \mathrm{H}, \mathrm{CH}_{3}\right), 1.33-1.41(\mathrm{~m}$, 1H), $1.72(\mathrm{~m}, 2 \mathrm{H}), 2.67\left(\mathrm{~s}, 3 \mathrm{H}, \mathrm{CH}_{3}\right)$, and 3.48-4.04 (m, 1H).

ITeAHGA: APCI-MS, m/z $266.0\left([\mathrm{M}-\mathrm{H}]^{-}\right)$. The ${ }^{1} \mathrm{HNMR}\left(600 \mathrm{MHz}, \mathrm{DMSO}-d_{6}\right.$, TMS): $\delta 0.88\left(\mathrm{~d}, J=6.59 \mathrm{~Hz}, 6 \mathrm{H}, 2 \mathrm{CH}_{3}\right), 1.29(\mathrm{ddd}, J=13.90,9.47,4.73 \mathrm{~Hz}, 1 \mathrm{H}$, $\mathrm{H}_{\mathrm{a}} \mathrm{CH}$ ), 1.48 (ddd, J=13.50, 9.31, 4.08 Hz,1H, $\mathrm{H}_{\mathrm{a}} \mathrm{CH}$ ), $1.86-1.75$ (m, 1H, CH), 2.61 (s, 3H, $\left.\mathrm{CH}_{3}\right), 3.73$ (dd, J=9.10, $\left.4.00 \mathrm{~Hz}, 1 \mathrm{H}\right), 7.69$ (s, 1H), 6.40 (s, br, 1H, NH), and 13.13 (s, br, $1 \mathrm{H}, \mathrm{COOH})$.

The production of immunogen and the homologous coating antigen was carried out by coupling the hapten ITeAHGA to the carrier protein (BSA/OVA) via the common 
N-hydroxysuccinimide active ester method, while ITeAH was conjugated to OVA and used as the heterologous coating antigen through the cross-linking agent glutaraldehyde. Successful conjugations were confirmed by the UV-vis data (data not shown). The antigen was added in molar excess over that of carrier protein in order to bind to sufficiently (Hamajima et al. 1995). Most reported hapten:protein ratios are between 50:1 to 100:1 which resulted in ideal artificial antigen and subsequently produced ideal antibodies (Hamajima et al. 1995; McAdam et al. 1992; Shen et al. 2007).

\section{2 mAb Production and Identification}

In our experiment, the mAb raised against ITeAH was successfully produced from a selected single hybridoma (2E8) and used to establish icELISA detection system for ITeA. The derivation strategy that is based on the special antibody to the derivative of the determinants, has been successfully used by other researchers to establish immunoassays for several haptens including 1-aminohydantoin (AHD) (Jiang et al. 2012), furaltadone metabolite AMOZ (Shen et al. 2012) and TeA (Prelle et al. 2013).

This strategy is particularly useful when production of antibody to toxic compound is in question, whether it is due to the extremely toxicity or the lack of toxic reagent itself. Considering the homologous coating antigens for which antibodies generally have weaker affinity towards (Xu et al. 2012; Galve et al. 2002), two coating antigens ITeAHGA-OVA and ITeAH-OVA were compared in the present study and the results (Fig. 3) clearly indicated that the heterologous coating antigen ITeAH-OVA $\left(\mathrm{IC}_{50}=\right.$ $14.5 \mathrm{ng} / \mathrm{mL})$ was superior to the homologous coating antigen ITeAHGA-OVA $\left(\mathrm{IC}_{50}=\right.$ $27.2 \mathrm{ng} / \mathrm{mL}$ ). This is in accordance with other research finding that the use of an appropriate heterologous coating antigen can significantly improve sensitivity of the assay (Qi et al. 2012). Subsequent experiments were therefore carried out based on the 
coating antigen of ITeAH-OVA.

\subsection{ELISA Optimization}

To optimize the developed ELISA, we tested various concentrations of the coating antigen and antibody, reaction time of antigen with antibody, incubation time of HRP labeled secondary antibody, different analyte/antibody ratio and buffering system. The $\mathrm{A}_{\max } / \mathrm{IC}_{50}$ ratio ( $\mathrm{A}_{\max }$ is the maximum value of absorbance) from the competition curves of ITeAH was used to estimate the influence of each condition on assay performance, and the higher ratio suggests the higher sensitivity of the assay (Liang et al. 2007). Figure 4(A) shows an optimal combination of a coating antigen at concentration of $15.6 \mathrm{ng} / \mathrm{mL}$ and an antibody at 1:2,000 dilution, exhibiting the lowest $\mathrm{IC}_{50}$ value of $5 \mathrm{ng} / \mathrm{ml}$. Other optimized assay conditions include 40 -min reaction time (Fig 4(B)) for incubation of the antigen-antibody, $30 \mathrm{~min}$ for the anti-IgG-HRP antibody (Fig 4(C)), and $\mathrm{H}_{2} \mathrm{O}$ was found as the most suitable diluent for the analyte (Fig 4(D)). Under these conditions, a calibration curve was constructed for ITeAH at concentration ranged from 0.064 to $1,000 \mathrm{ng} / \mathrm{mL}$ with a linear working range between 1.7 and $36.4 \mathrm{ng} / \mathrm{mL}\left(\mathrm{R}^{2}=0.9944\right)$ (Fig. 5). The established icELISA system is highly sensitive with an $\mathrm{IC}_{50}$ value of $7.8 \mathrm{ng} / \mathrm{mL}$ and a LOD of $0.5 \mathrm{ng} / \mathrm{mL}$ for ITeAH. An enzyme immunoassay has been reported for TeA in apple and tomato products with an $\mathrm{IC}_{50}$ of $320 \pm 130 \mathrm{ng} / \mathrm{ml}$ for TeA, but a much lower $\mathrm{IC}_{50}$ of $23.3 \pm 7.5 \mathrm{ng} / \mathrm{ml}$ for the TeA acetate. When TeA acetate was employed as the standard in the EIA to measure the acetylated $\mathrm{TeA}$, an $\mathrm{IC}_{30}$ of $5.4 \pm 2.0 \mathrm{ng} / \mathrm{ml}$ was resulted (Gross et al. 2011). Ackermann et al.(2011) described the development of an EIA for rapid determination of alternariol, another Alternaria mycotoxin, with a detection limit of $1-2 \mu \mathrm{g} / \mathrm{kg}$.

\subsection{Cross-reactivity Studies}

The specificity of the developed monoclonal antibody was examined by testing the 
cross-reactivity (CR) rates of several Alternaria mycotoxin analogues (Table 1), including iso-tenuazonic acid (ITeA), tenuazonic acid (TeA), alternariol (AOH), alternariol methyl ether (AME), and hydrazine hydrate. The results were all less than $0.1 \%$, suggesting the high specificity of the produced monoclonal antibody towards ITeAH, which is vital in the developed ELISA system.

\subsection{Analysis of Spiked Samples}

Spiked apple juice, beer, and tomato ketchup samples were analyzed using the developed ELISA. It is generally recognized that the reasonable sample preparation can effectively reduce the matrix effect (Sheng et al. 2012). A simple $\mathrm{H}_{2} \mathrm{O}$ dilution of samples was used in this study, i.e., 35 times dilution for the extracts of apple juice and beer, and 45-fold dilution for extract of tomato ketchup. Samples were spiked with ITeA at different concentrations to evaluate the recovery rates of the developed immunoassay. As shown in Table 2, the recoveries of ITeA ranged from 93.3\% to $109.8 \%$ for apple juice, $82.3 \%$ to $93.2 \%$ for beer, and $93.2 \%$ to $107.3 \%$ for tomato ketchup, respectively, and that was within the general requirement of $70-120 \%$ for screening immunoassays (Kondo et al. 2012; Wang et al. 2011). The coefficients of variation $(\mathrm{CV})$ were all found to be less than $15 \%$, indicating a good level of precision of the developed ELISA.

\subsection{Comparison of the ELISA and HPLC-MS/MS Method}

The ELISA results were compared and confirmed by the HPLC-MS/MS method. The linear relationship between the two methods was at $y=0.7660 x+45.52$ with a squared coefficient of correlation $\left(\mathrm{R}^{2}\right)$ of 0.9557 for the spiked food samples (Fig. 6), suggesting a good agreement between the screening ELISA and confirmatory HPLC-MS/MS methods. These results also demonstrated the suitability of the developed ELISA for the detection of trace levels of ITeA in food samples. Asam et al. 
(2013) reported the development of analytical methods for detection of TeA and its analogues in foods with an LOD of $1 \mu \mathrm{g} / \mathrm{kg}$ (TeA) and $3 \mu \mathrm{g} / \mathrm{kg}$ (ITeA) for derivatized samples and $60 \mu \mathrm{g} / \mathrm{kg}$ (TeA and ITeA) for samples without derivatization, while the ELISA method we developed here has a significantly lower LOD of $0.5 \mu \mathrm{g} / \mathrm{L}$ for ITeA. Taking consideration of the generally lower level of ITeA than TeA in fruits and vegetables, the present ITeA ELISA possesses lower detection limit and higher sensitivity.

\subsection{Detection of ITeA in real samples}

The commercial food samples $(n=20)$ were analyzed using both ELISA and HPLC-MS/MS methods. As shown in Table 3, results revealed a highly conformity between the two methods, i.e., all samples were found to be positive by the developed ELISA and their quantified results are in consistence with the HPLC-MS/MS data. This further confirms the reliability of the established ELISA method as a fit-for-purpose screening tool for quantitative analysis of ITeA in food samples. ITeA was detected with varying concentrations in all samples tested, i.e., $39.2-110.3 \mathrm{ng} / \mathrm{mL}$ in apple juice, $45.4-79.3 \mathrm{ng} / \mathrm{mL}$ in beer, $41.5-81.1 \mathrm{ng} / \mathrm{mL}$ in tomato ketchup and 43.4-157.2 $\mathrm{ng} / \mathrm{mL}$ in dried fruits. Using the UPLC-ESI-MS/MS, Walravensa et al. (2014) reported around $71 \%$ of rice samples and $31 \%$ of oat flake samples obtained in Belgium were contaminated with TeA at concentrations ranging from 1.90-113 $\mu \mathrm{g} / \mathrm{kg}$ and 2.13-39 $\mu \mathrm{g} / \mathrm{kg}$, respectively. Such high frequency and levels of contamination of Alternaria mycotoxins and TeA in particular has highlighted the importance of continued monitoring of TeA in food and feed. Likewise, similar occurrence will also be applied to ITeA contamination scenario. 

limits (MRL) available for ITeA. Moreover, due to a lack of information on occurrence and toxicity, the European Food Safety Authority (EFSA) stated that a risk assessment for Alternaria mycotoxins in feed was not possible (EFSA, 2011). This may partially due to the lack of rapid methods such as immunoassays that are capable of screening a large number of samples within a relatively short period of time. Consequently, the liquid chromatography coupled to (tandem) mass spectrometry is the method of choice for quantification of Alternaria toxins in foods and feeds. The sensitive and reliable ELISA described in this study would therefore contribute greatly to the effective and efficient monitoring of ITeA in food and the environment.

\section{Conclusions}

401 In this paper, we report the development of a sensitive ELISA using a specific 402 monoclonal antibody for reliable detection of ITeA in food samples. The optimized 403 ELISA has an $\mathrm{IC}_{50}$ value of $7.8 \mathrm{ng} / \mathrm{mL}$ and a detection limit of $0.5 \mathrm{ng} / \mathrm{mL}$ with good 404 extraction efficiency for apple juice, beer, and tomato ketchup samples. The established immunoassay was subsequently implemented in a mini-survey of commercial food samples with results revealing a potentially widespread 407 contamination of ITeA (probably alongside TeA) in processed commercial foods. The 408 close agreement between the ELISA result and HPLC-MS/MS data has confirmed the 409 reliability of this newly developed ELISA as a versatile screening tool for monitoring 410 ITeA in different foods. Future studies will seek its applications in a wider range of 411 foodstuffs including animal feeds to facilitate the collection of occurrence data and 412 estimation of dietary exposure for this Alternaria mycotoxin. 
415 Funding: This study was funded by the National Natural Science Foundation of 416 China (31271866), the National Key Research and Development Program of China 417 (2016YFE0106000), the Science and Technology Project of Guangzhou City 418 (2014J4100185), and the Science and Technology Project of Guangdong Province 419 (2014A050503059, 2014A030311043).

420 Conflict of Interest: All authors declare no conflict of interest.

421 Ethical approval: All procedures involving animals were approved and performed 422 in accordance with the relevant protective and administrative guidelines for laboratory 423 animals of China.

424 Informed consent: Informed consent was obtained from all individual participants 425 included in the study.

426 


\section{References}

429

430

[1] S. Qiang, Y.F. Dong, C.F. An, B. Zhou, Y.Z. Zhu, S.G. Chen, X.B. Dai, B.J. Dai, J.G. Cai (2008). Biological control of weeds using the metabolites of Alternaria Alternata. U.S. Patent /0280761, A1, 2008.

[2] S. Marin, A.J. Ramos, G. Cano-Sancho, V. Sanchis (2013). Mycotoxins: Occurrence, toxicology, and exposure assessment. Food Chem. Toxicol., 60: 218-237.

[3] D. Siegel, M. Feist, M. Proske, M. Koch, I. Nehls (2010). Degradation of the Alternaria mycotoxins alternariol, alternariol monomethyl ether, and altenuene upon bread baking. J. Agric. Food Chem., 58: 9622-9630.

[4] EFSA Panel on Contaminants in the Food Chain (CONTAM) (2011). Scientific opinion on the risks for animal and public health related to the presence of Alternaria toxins in feed and food. EFSA J., 9(10): 2407.

[5] G.S. Shephard, F. Berthiller, P.A. Burdaspal, C. Crews, M.A. Jonker, R. Krska, S. MacDonald, R.J. Malone, C. Maragos, M. Sabino, M. Solfrizzo, H.P. Van Egmond a, T.B. Whitaker (2012). Developments in mycotoxin analysis: an update for 2011-2012. World Mycotoxin J., February, 5 (1): 3-30.

[6] J.C. Qin, Y.M. Zhang, L. Hu, Y.T. Ma, J.M. Gao (2009). Cytotoxic metabolites produced by Alternaria No.28, an endophytic fungus isolated from Ginkgo biloba. Nat. Prod. Commun. , 4(11): 1473-1476.

[7] C.O. Gitterman (1965). Antitumor, cytotoxic, and antibacterial activities of tenuazonic acid and congeneric tetramic acids. J. Med. Chem., 8(4): 483-486.

[8] M.H. Lebrun, L. Nicolas, M. Boutar, F. Gaudemer, S. Ranomenjanahary, A. Gaudemer (1988). Relationship between the structure and the phytotoxicity of the fungal toxin tenuazonic acid. Phytochemistry, 27 (1): 77-84.

[9] S. Asam, M. Lichtenegger, K. Muzik, Y. Liu, O. Frank, T. Hofmann, M. Rychlik (2013). Development of analytical methods for the determination of tenuazonic acid analogues in food commodities. J. Chromatogr. A, 1289:27-36. 
[10]K. Zhao, B. Shao, D.J. Yang, F.Q. Li (2015). Natural occurrence of four alternaria mycotoxins in tomato- and citrus- based foods in China. J. Agric. Food Chem., 63: 343-348.

[11]K. Zhao, B. Shao, D.J. Yang, F.Q. Li, J.H. Zhu (2015). Natural occurrence of alternaria Toxins in wheat-based products and their dietary exposure in China. PLoS One, Jun 29, 10(6): e0132019.

[12]J. Noser, P. Schneider, M. Rother, H. Schmutz (2011). Determination of six Alternaria toxins with UPLC-MS/MS and their occurrence intomatoes and tomato products from the Swiss market. Mycotoxin Res, 27: 265-271.

[13]D. Siegel, T. Rasenko, M. Koch, I. Nehls (2009). Determination of the Alternaria mycotoxin tenuazonic acid in cereals by high-performance liquid chromatography-electrospray ionization ion-trap multistage mass spectrometry after derivatization with 2,4-dinitrophenylhydrazine. J. Chromatogr. A, 1216: $4582-4588$.

[14] S. Asam, Y. Liu, K. Konitzer, M. Rychlik (2011). Development of a stable isotope dilution assay for tenuazonic acid. J. Agri. Food Chem., 59: 2980-2987.

[15]A. Prelle, D. Spadaro, A. Garibaldi, M.L. Gullino (2013). A new method for detection of five alternaria toxins in food matrices based on LC-APCI-MS. Food Chem., 140: 161-167.

[16]M. Gross, V. Curtui, Y. Ackermann, H. Latif, E. Usleber (2011). Enzyme immunoassay for tenuazonic acid in apple and tomato products. J. Agric. Food Chem., 59: 12317-12322.

[17]X.X. Yang, X.X. Liu, H. Wang, Z.L. Xu, Y.D. Shen, Y.M. Sun (2012). Development of an enzyme-linked immunosorbent assay method for detection of tenuazonic acid. Chinese J. Anal. Chem., 40(9): 1347-1352.

[18]K. Hamajima, H. Bukawa, J. Fukushima, S. Kawamoto, T. Kaneko, K.I. Sekigawa, S.I. Tanaka, M. Tsukuda, K. Okuda (1995). A macromolecular multicomponent peptide vaccine prepared using the glutaraldehyde conjugation method with strong immunogenicity for HIV-1. Clin. Immunol. Immunopathol., 77: 374-379. 
[19]D.P. McAdam, A.S. Hill, H.L. Beasley, J.H. Skerritt (1992). Mono- and polyclonal antibodies to the organophosphate fenitrothion.1.Approaches to hapten-protein conjugation. J. Agric. Food Chem., 40: 1466-1470.

[20]M.J. Moreno, A. Abad, A. Montoya (2001). Production of monoclonal antibodies to the N-methylcarbamate pesticide propoxur. J. Agric. Food Chem., 49: 72-78.

[21]M.P. Zhao, Y.Z. Li, Z.Q. Guo, X.X. Zhang, W.B. Chang (2002). A new competitive enzyme-linked immunosorbent assay (ELISA) for determination of estrogenic bisphenols. Talanta, 57: 1205-1210.

[22] M.C. Henniona, D. Barcelob (1998). Strengths and limitations of immunoassays for effective and efficient use for pesticide analysis in water samples: A review. Anal. Chim. Acta, 362: 3-34.

[23]J.L. Cui, K. Zhang, Q.X. Huang, Y.Y. Yu, X.Z. Peng (2011). An indirect competitive enzyme-linked immunosorbent assay for determination of norfloxacin in waters using a specific polyclonal antibody. Anal. Chim. Acta, 688: 84-89.

[24]E.E. Stinson, S.F. Osman, E.G. Heisler, J. Siciliano, D.D. Bills (1981). Mycotoxin production in whole tomatoes, apples, oranges, and lemons. J. Agric. Food Chem., 29: 790-792.

[25] Y.D. Shen, Y. Wang, S.W. Zhang, Z.L. Xiao, Y.M. Sun, X.Z. Bu, L.Q. Gu (2007). Design and efficient synthesis of novel haptens and complete antigens for the AOZ, a toxic metabolite of furazolidone. Chinese Chem. Lett., 18: 1490-1492.

[26]J.V. Mercader, C. Suárez-Pantaleón, C. Agulló, A. Abad-Somovilla, A. Abad-Fuentes (2008). Production and characterization of monoclonal antibodies specific to the strobilurin pesticide pyraclostrobin. J. Agri. Food Chem., 56: $7682-7690$.

[27] W.X. Jiang, P.J. Luo, X. Wang, X. Chen, Y.F. Zhao, W. Shi, X.P. Wu, Y.N. Wu, J.Z. Shen (2012). Development of an enzyme-linked immunosorbent assay for the detection of nitrofurantoin metabolite, 1-amino-hydantoin, in animal tissues. Food Control, 23: 20-25.

[28] Y.D. Shen, Z.L. Xu, S.W. Zhang, H. Wang, J.Y. Yang, H.T. Lei, Z.L. Xiao, Y.M. 21

Sun (2012). Development of a monoclonal antibody-based competitive indirect 
enzyme-linked immunosorbent assay for furaltadone metabolite AMOZ in fish and shrimp samples. J. Agric. Food Chem., 60: 10991-10997.

518 [29]Z.L. Xu, Y.D. Shen, Y.M. Sun, K. Campbell, Y.X. Tian, S.W. Zhang, H.T. Lei, 519 Y.M. Jiang (2012). Novel hapten synthesis for antibody production and development of an enzyme-linked immunosorbent assay for determination of

[32]C.Z. Liang, R.Y. Jin, W.J. Gui, G.N. Zhu (2007). Enzyme-linked immunosorbent assay based on a monoclonal antibody for the detection of the insecticide triazophos: assay optimization and application to environmental samples. Environ. Sci. Technol, 41: 6783-6788.

[33]Y. Ackermann, V. Curtui, R. Dietrich, M. Gross, H. Latif, E. Martlbauer, E. Usleber (2011). Widespread occurrence of low levels of alternariol in apple and tomato products, as determined by comparative immunochemical assessment using monoclonal and polyclonal antibodies. J. Agric. Food Chem., 59: 6360-6368.

[34]Y.J. Sheng, W.X. Jiang, S.D. Saeger, J.Z. Shen, S.X. Zhang, Z.H. Wang (2012). Development of a sensitive enzyme-linked immunosorbent assay for the detection of fumonisin $\mathrm{B}_{1}$ in maize. Toxicon, 60: 1245-1250.

[35]M. Kondo, K. Tsuzuki, H. Hamada, Y. Yamaguchi, M. Uchigashima, M. Saka, E. Watanabe, S. Iwasa, H. Narita, S, Miyake (2012). Development of an enzyme-linked immunosorbent assay (ELISA) for residue analysis of the fungicide azoxystrobin in agricultural products. J. Agric. Food Chem., 60: 904-911. 
546 [36] J.P. Wang, G.C. Yu, W. Sheng, M. Shi, B.X. Guo, S. Wang (2011). Development 547 of an enzyme-linked immunosorbent assay based a monoclonal antibody for the 548 detection of pyrethroids with phenoxybenzene multiresidue in river water. J. Agric. $549 \quad$ Food Chem., 59: 2997-3003.

550 [37]J. Walravensa, H. Mikulab, M. Rychlikc, S. Asamd, E.N. Ediagea, J.D.D. 551 Mavungua, A.V. Landschoote, L. Vanhaeckef, S.D. Saeger (2014). Development 552 and validation of an ultra-high-performance liquid chromatography tandem mass 553 spectrometric method for the simultaneous determination of free and conjugated 554 Alternaria toxins in cereal-based foodstuffs. J. Chromatogr. A, 1372: 91-101. 555 
557 Table 1. Cross-reactivity (CR) of the novel mAb with ITeAH and other compounds

558 using the indirect competitive ELISA developed.

559

$\begin{array}{cccc}\text { Compound } & \text { Cross-reactivity } \\ \text { (E)-3-(1-hydrazonoethyl) }\end{array}$


561 Table 2. Recoveries of ITeA from spiked apple juice, beer, and tomato ketchup by 562 icELISA $(\mathrm{n}=3)$.

\begin{tabular}{lccc}
\hline \multirow{2}{*}{ Matrix } & $\begin{array}{c}\text { ITeA spiked concentration } \\
(\mathrm{ng} / \mathrm{mL} \text { or } \mathrm{ng} / \mathrm{g})\end{array}$ & \multicolumn{2}{c}{ icELISA found $(\mathrm{ng} / \mathrm{mL}$ or $\mathrm{ng} / \mathrm{g})$} \\
\cline { 3 - 4 } & 30 & Recovery $\pm \mathrm{SD}(\%)$ & $\mathrm{CV}(\%)$ \\
\hline apple & 150 & $93.3 \pm 10.2$ & 10.9 \\
juice & 300 & $98.7 \pm 9.8$ & 9.9 \\
& 150 & $109.8 \pm 10.6$ & 9.7 \\
beer & 300 & $89.1 \pm 7.9$ & 8.8 \\
& 720 & $93.2 \pm 8.2$ & 8.8 \\
& 150 & $82.3 \pm 3.6$ & 4.4 \\
tomato & 300 & $94.3 \pm 9.7$ & 10.3 \\
ketchup & 720 & $93.2 \pm 11.4$ & 12.2 \\
& & $107.3 \pm 6.5$ & 6.1 \\
\hline
\end{tabular}

563 
565 Table 3. Concentrations of ITeA in food samples determined by icELISA and 566 HPLC-MS/MS.

\begin{tabular}{cccccccc}
\hline Sample & Number & $\begin{array}{c}\text { icELISA } \\
(\mathrm{ng} / \mathrm{mL} \text { or } \mathrm{ng} / \mathrm{g})\end{array}$ & $\begin{array}{c}\text { HPLC-MS/MS } \\
(\mathrm{ng} / \mathrm{mL} \text { or ng/g) }\end{array}$ & Sample & Number & $\begin{array}{c}\text { icELISA } \\
(\mathrm{ng} / \mathrm{mL} \text { or } \\
\mathrm{ng} / \mathrm{g})\end{array}$ & $\begin{array}{c}\text { HPLC-MS/MS } \\
(\mathrm{ng} / \mathrm{mL} \text { or } \\
\mathrm{ng} / \mathrm{g})\end{array}$ \\
\hline apple & 1 & $39.2 \pm 3.1$ & $44.6 \pm 5.2$ & $\begin{array}{c}\text { tomato } \\
\text { ketchup }\end{array}$ & 1 & $41.5 \pm 4.1$ & $39.5 \pm 4.4$ \\
juice & 2 & $98.5 \pm 9.4$ & $103.5 \pm 8.1$ & & $81.1 \pm 8.5$ & $96.4 \pm 11.4$ \\
& 3 & $110.3 \pm 10.2$ & $102.8 \pm 13.9$ & & 3 & $28.1 \pm 2.4$ & $39.4 \pm 3.8$ \\
& 4 & $68.4 \pm 5.1$ & $76.6 \pm 6.4$ & & 4 & $30.6 \pm 1.9$ & $38.1 \pm 5.9$ \\
& 5 & $82.9 \pm 7.5$ & $79.0 \pm 8.6$ & dried & 1 & $48.4 \pm 2.2$ & $43.5 \pm 1.6$ \\
beer & 1 & $45.4 \pm 6.7$ & $40.8 \pm 3.9$ & fruit & 2 & $83.8 \pm 10.6$ & $92.1 \pm 6.4$ \\
& 2 & $76.2 \pm 7.9$ & $83.5 \pm 9.7$ & & 3 & $76.6 \pm 6.9$ & $84.7 \pm 9.4$ \\
& 3 & $69.8 \pm 4.3$ & $80.7 \pm 7.3$ & & 4 & $157.2 \pm 1.3$ & $156.9 \pm 2.7$ \\
& 4 & $79.3 \pm 6.7$ & $81.9 \pm 10.5$ & & 5 & $52.2 \pm 0.7$ & $47.4 \pm 0.5$ \\
& 5 & $73.5 \pm 8.9$ & $68.4 \pm 9.5$ & & 6 & $43.4 \pm 1.3$ & $44.1 \pm 0.7$ \\
\hline
\end{tabular}




\section{$569 \quad$ Figure captions}

570 Fig. 1. Chemical structures of TeA, ITeA and its derivatives, ITeAH and ITeAHGA.

571 Fig. 2. Synthesis route of hapten ITeA and the derivatives of ITeAH and ITeAHGA.

572 Fig. 3. Dose-dependent indirect competitive ELISA curves for ITeAH against two

573 coating antigens. The error bar represents the standard deviation of the mean $(n=3)$.

574 Fig. 4. Optimization of assay conditions: (A) coating antigen concentration and 575 antibody dilution; (B) competition time of antigen-antibody; (C) IgG-HRP incubation 576 time; and (D) the diluting factor of the analyte.

577 Fig. 5. Calibration curve for the detection of ITeAH by icELISA. Each point 578 represents the mean results of four replicates. The vertical bars indicate the mean 579 results of the standard deviation.

580 Fig. 6. Comparison of icELISA and HPLC-MS/MS results for ITeA quantification. 
<smiles>CCC(C)C1NC(=O)C(C(C)=O)=C1O</smiles>

TeA

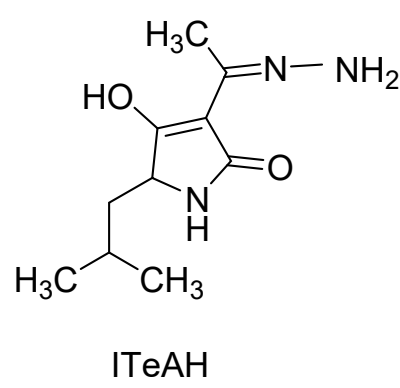

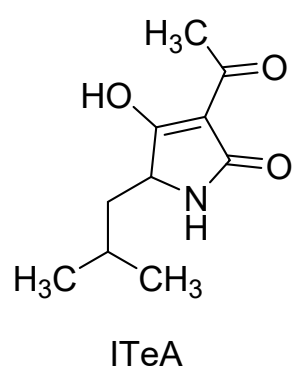

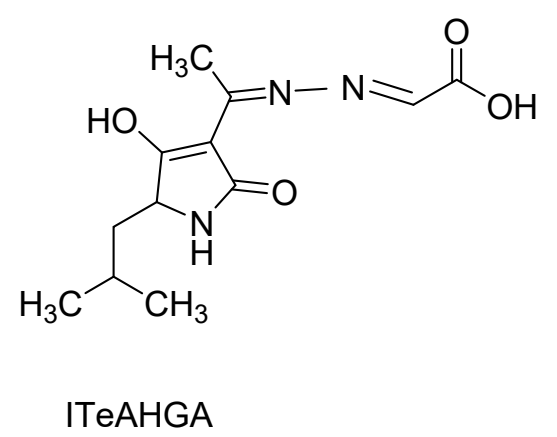

Fig. 1 


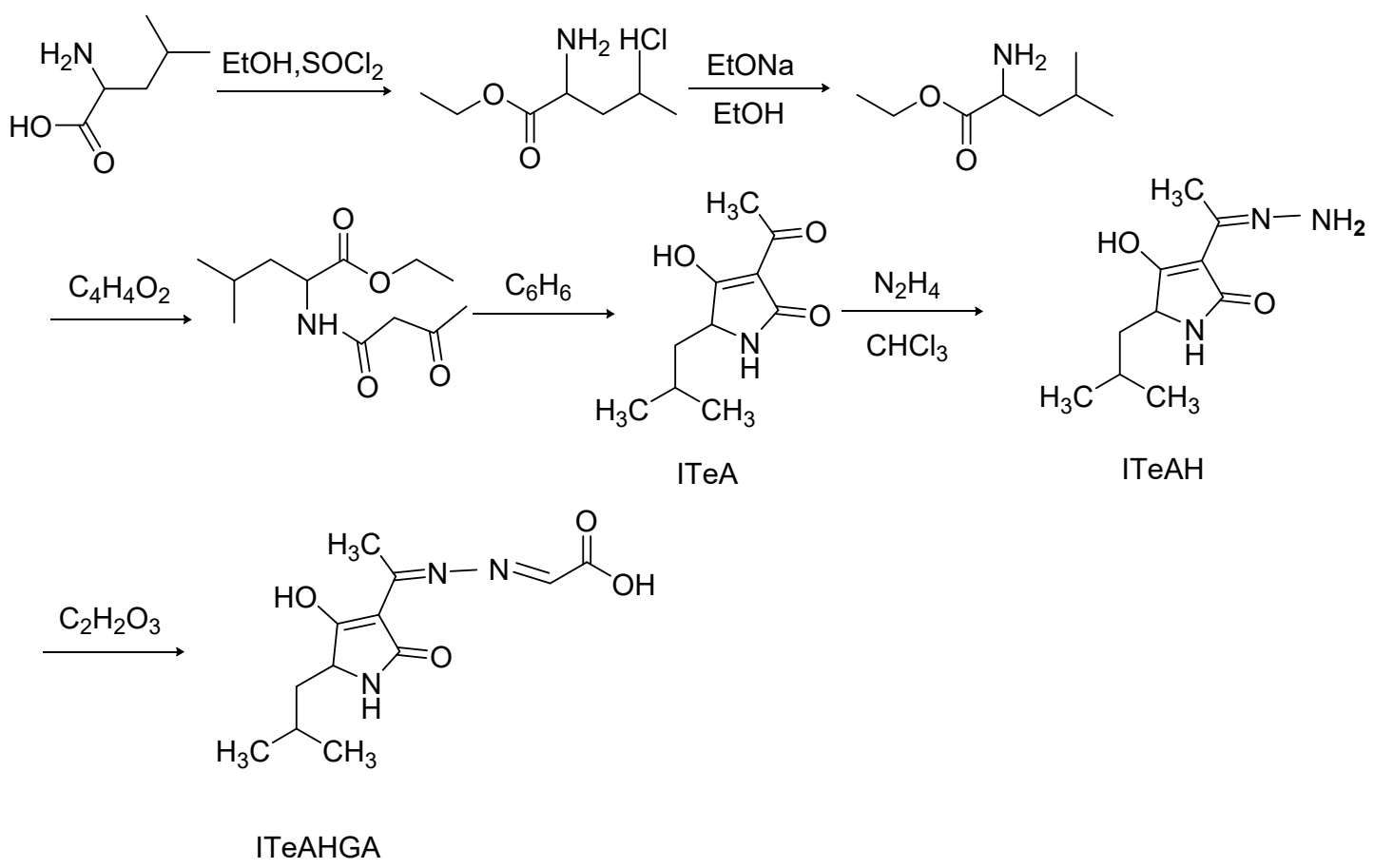

Fig. 2 


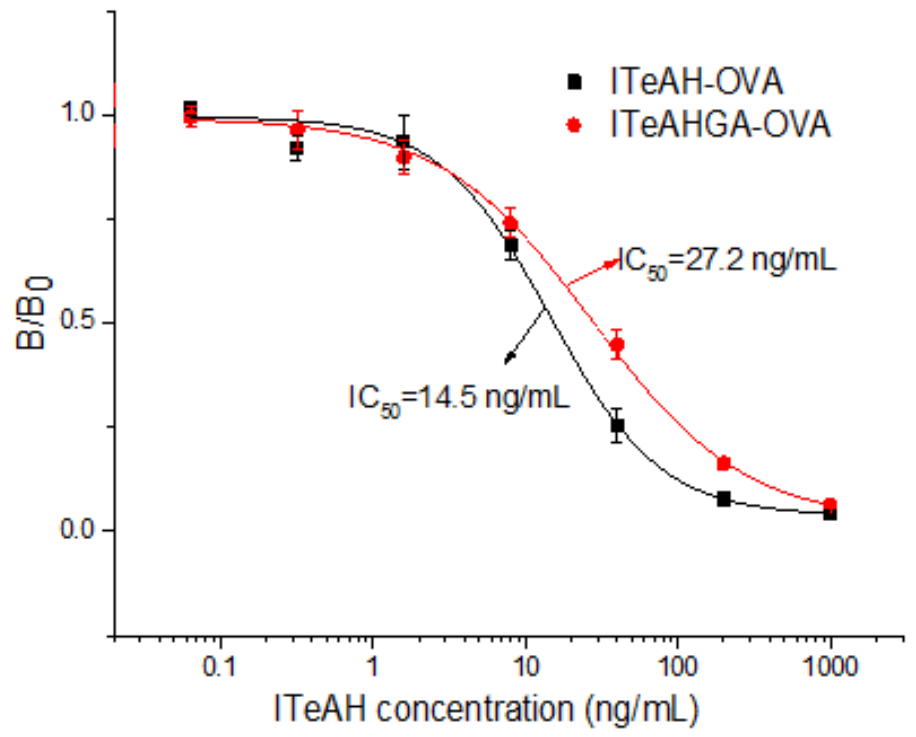

Fig. 3 

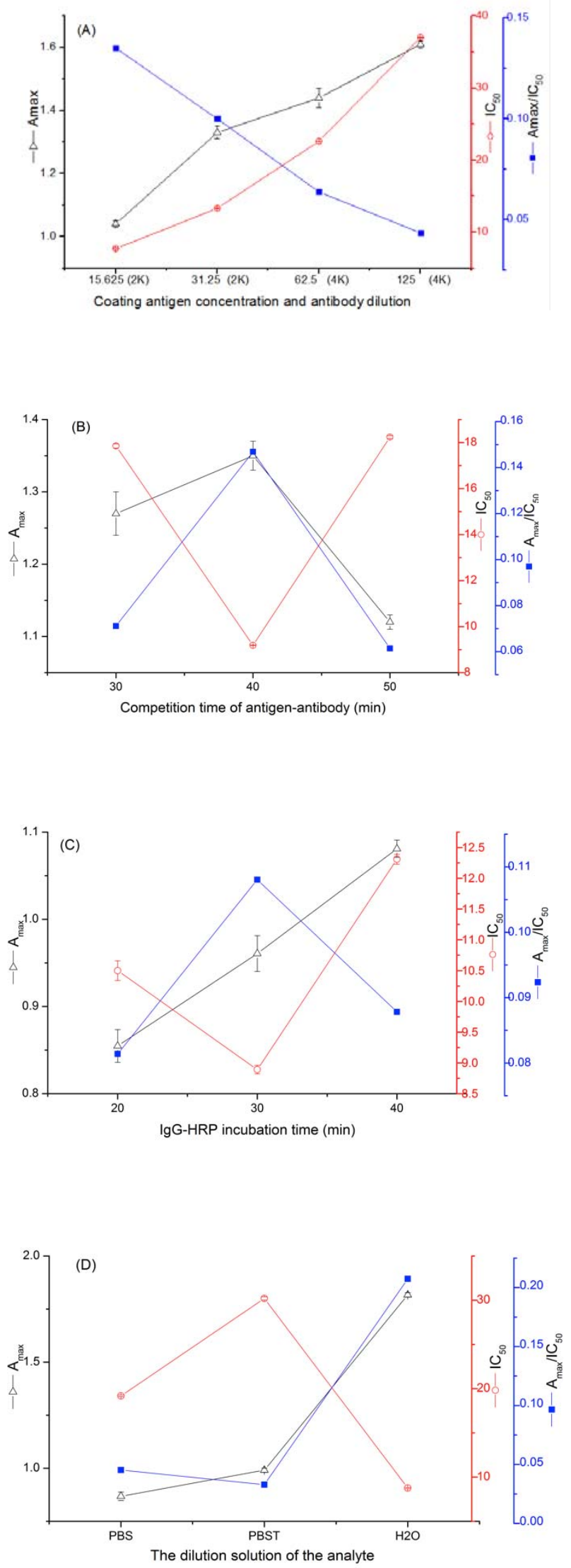

Fig. 4 




Fig. 5 


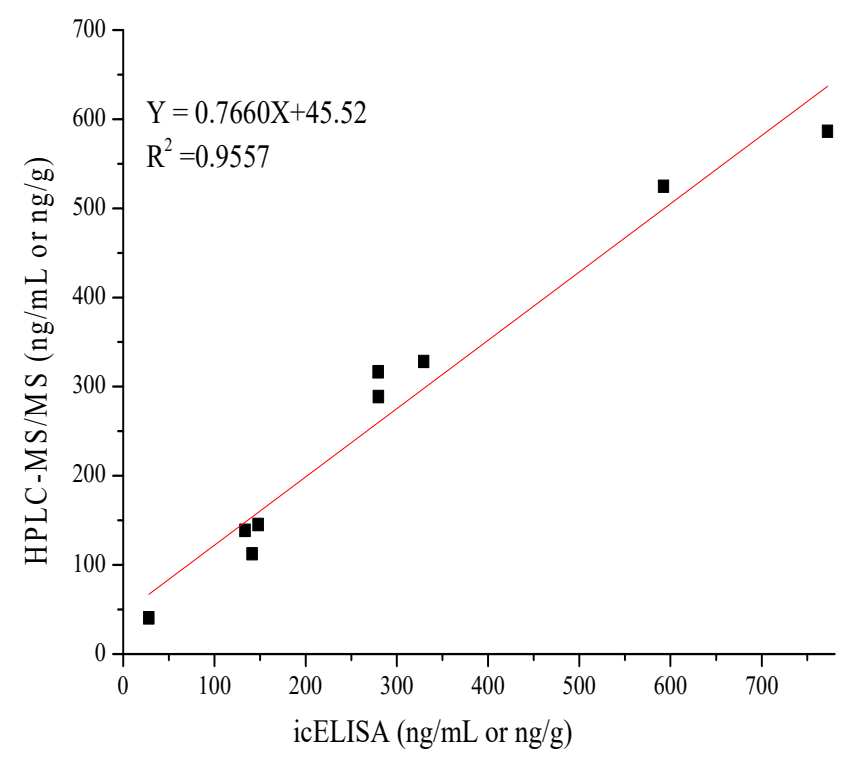

Fig. 6 